\title{
Design Considerations for 5G Base Stations to Reduce 5G Core Network and S1 Interface Load
}

\author{
Deussom Djomadji Eric Michel \\ Department of Electrical \\ and Telecommunications Engineering; \\ National Advanced Schoo \\ I of Engineering of Yaoundé; \\ University of Yaoundé I, CAMEROON
}

\author{
Tonye Emmanuel \\ Department of Electrical \\ and Telecommunications Engineering; \\ National Advanced School of \\ Engineering of Yaoundé; \\ University of Yaoundé I, CAMEROON
}

\begin{abstract}
In this paper it is proposed to modify the existing base stations (such as eNodeBs) by adding a new base band board in the $5 \mathrm{G}$ base station (5G eNodeB) to serve as a cache and storage unit in order to avoid the $5 \mathrm{G}$ core network $(5 \mathrm{G} \mathrm{CN})$ to send to users under the same $5 \mathrm{G}$ eNodeB the same multimedia contents like high definition video multiple times. A copy of the contents will be saved in the new base band board so that if one user needs it, after sending the request to the $5 \mathrm{G} \mathrm{CN}$, the $5 \mathrm{G} \mathrm{CN}$ will negotiate with the $5 \mathrm{G}$ eNodeB to check if the requested contents are available at its level. If that is the case, the $5 \mathrm{G} \mathrm{CN}$ will authorize the $5 \mathrm{G}$ eNodeB to send multimedia contents directly to the user without downloading it again from the internet. In this process, the load on the S1 interface and the link between the $5 \mathrm{G} \mathrm{CN}$ and the internet will be reduced, thus optimizing available resources in both $5 \mathrm{G} \mathrm{CN}$ and IP transmission. This solution will increase user quality experience and drastically reduce latency in the network.
\end{abstract}

\section{General Terms}

eNodeB for $5 \mathrm{G}$ network.

\section{Keywords}

$5 \mathrm{G}$ network, eNodeB, Core network, S1 interface, distributed storage unit.

\section{INTRODUCTION}

The future of mobile communications will be different to the existing $3 \mathrm{G} / 4 \mathrm{G}$ network which is being used today. The demand for mobile broadband will continue to increase creating new challenges and constraints with the introduction of services like mobile multimedia services based on OTT, high definition video and better streams, online gaming and so on. Objects ranging from cars and factory machines, appliances to watches and apparel, will learn and organize themselves to fulfill our needs by automatically adapting to our behavior, environment or business processes [1]. New uses will arise, many not yet conceived, creating novel requirements that communications networks must be able to meet flexibly and cost effectively in order to support operator profitability and the wider ecosystem. Networks must, therefore, evolve to become personalized, by implying to be able to meet the diverse needs of users, whether human or non-human. According to a Nokia study, by 2025 , there will be ten to one hundred (10-100) times more devices connected than humans. Many applications will need reliable communication links with low latency and extreme throughput. Public safety and business critical applications will run on the cellular network, requiring stringent and reliable service levels for capacity, throughput and latency [2].
A large number of real-time applications will demand end-toend network latency of single digit milliseconds to avoid perceivable lags in browsing or videos, or to control drones and robots. Networks in the $5 \mathrm{G}$ era will achieve $1 \mathrm{~ms}$ network latency, which is far better than the 15 to $20 \mathrm{~ms}$ that today's best LTE networks can achieve. As such, the overall performance of mobile networks will increase dramatically.

Finally it can be seen that future networks will be programmable platforms offering not just voice and data [1], but supporting diverse uses, services and applications. With all these demands of multimedia services, something should be done at the $5 \mathrm{G}$ eNodeB side to fulfill all the needs of both humans and things in the 5G network [3] [4] [5] [6]. To fulfill $4 \mathrm{G}$ requirements, the existing $3 \mathrm{G}$ NodeB have evolved to eNodeB, the $3 \mathrm{G}$ RNC is no more present in $4 \mathrm{G}$ network, and functions of RNC have been transferred to NodeB to create the eNodeB (evolved NodeB). In the same way, something should be done to adapt the eNodeB for $5 \mathrm{G}$ requirements. For example, Chadan et al [7] have proposed to modify eNodeBs and User equipments to support full duplex transmission in $5 \mathrm{G}$ networks.

The objective of this article is to propose a solution that consists of adding a new board on the $5 \mathrm{G}$ eNodeB namely a cache and storage board. This new board will be used to save common contents like high definition video (HD video) so that according to the demand by users connected to that $5 \mathrm{G}$ eNodeB, the content can be directly forwarded to users without increasing the load of the S1 interface, and the 5G CN by downloading the content multiple times from internet.

This article is organized as follows: section $I$ is an overall introduction and perspective of the $5 \mathrm{G}$ mobile era, section II will present the structure of existing eNodeBs focusing on the distributed base station, followed by a proposed solution in section III. Section IV, presents an evaluation of the advantages and possible disadvantages that we may have at $\mathrm{S} 1$ interface, $5 \mathrm{G} \mathrm{CN}$ side, and the link between the 5G CN and internet side, and lastly a conclusion.

\section{EXISTING eNodeB BASED ON DISTRIBUTED BASE STATION}

All the vendors worldwide have adopted the distributed base station (DBS) in their wireless access network product. The DBS is made up of three subsystems, the base band sub system commonly called the Base band unit (BBU), the RF subsystem that consists of the remote radio unit (RRU) also called the remote radio head (RRH), antennas and CPRI cables that allow the connection between the BBU and the RRU. Let us now focus on the BBU. 
The BBU is a baseband processing unit that centrally manages the entire base station.

The BBU provides the following functions:

- Manages the entire base station system in terms of operation, maintenance, signaling processing, and system clock.

- Processes uplink and downlink data, and provides common public radio interfaces (CPRIs) for the communication between the BBU and RF modules.

- Provides physical ports for information exchange between the base station and the transport network.

- Provides an OM channel between the base station and the operation and maintenance center (OMC).

- $\quad$ Provides ports for receiving and transmitting signals from environment monitoring devices.

Most vendors have assigned these functions to different boards, namely there is a board responsible for transmission, another board responsible for technology channel processing. For instance, a board processes LTE signals and another one is in charge of the maintenance and management of the whole DBS.

Some vendors have combined the transmission function, the maintenance and management functions into one board. So finally the existing $\mathrm{BBU}$ for most vendors has two or three boards in total, while the BBU is sometimes designed with 8 slots; taking the examples of HUAWEI BBU, ZTE BBU and even ALCATEL LUCENT BBU [8] [9]. The following picture is given as an example.

\begin{tabular}{|l|l|l|}
\hline Slot 0 & Slot 4 \\
\cline { 2 - 3 } & Slot 1 & Slot 5 \\
\hline Slot 2 & Slot 6 \\
\cline { 2 - 3 } $\begin{array}{c}\text { (Slot 3) Technology } \\
\text { processing board } \\
\text { (for example LTE) }\end{array}$ & $\begin{array}{l}\text { (Slot 7) Management } \\
\text { and transmission board }\end{array}$ \\
\hline
\end{tabular}

Fig 1: Example of BBU boards allocation [10]

So amongst the 8 available slots only two or three are mostly used.

\section{PROPOSED SOLUTION FOR 5G eNodeB}

The solution proposed for the $5 \mathrm{G}$ eNodeB is to design a new board in charge of local cache and storage at the BBU level to save the contents mostly used by subscribers. For example, in an area with University subscribers connected to social networks, the YouTube platform and so on, watching videos and sharing contents; instead of downloading the contents every single time from the web which ultimately increases the capacity usage in air interface, $\mathrm{S} 1$ interface, $5 \mathrm{G} \mathrm{CN}$ and finally between $5 \mathrm{G} \mathrm{CN}$ and the internet servers, sometimes causing congestion, a part of the contents for the most part multimedia contents, could be saved in the BBU. Now the storage capacity is no more a problem in a board. With a small physical size it is possible to install a hard disk with 10 TO (Tera octets) as capacity.

Let us consider figure 2 diagram for a typical $4 \mathrm{G}$ network.

Looking at the architecture of a typical 4G network, when users are downloading multimedia contents, the network will send contents to each user per demand even if the contents per user are the same ( Figure 2). This will cause a waste of bandwidth at the S1 interface level, EPC level and even on the internet link level. And in the situation of high traffic, the user experience could be reduced and even the global quality of service in the network due to congestion on the IP transport network, congestion on the $5 \mathrm{G} \mathrm{CN}$ and high demand on the internet link. Figure 3 below, illustrates a typical $4 \mathrm{G}$ eNodeB with its attached Users

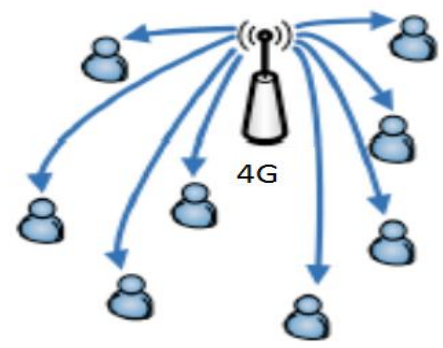

Fig 2: Content delivery from eNodeB to attached Users

It can be seen in Figure 4 below that the same multimedia content is sent three (03) times by the EPC to users while this could be reduced. Figure 5, shows how one cache and storage board is added at $5 \mathrm{G}$ eNodeB level, the $5 \mathrm{G}$ eNodeB will distribute the contents to UEs; this will avoid wasting resources and capacity on $\mathrm{S} 1$ link, $5 \mathrm{G} \mathrm{CN}$ and the internet link.

In Figure 6, we can see the huge usage of eNodeB capacity by different kind of users (human and device), this show the importance to relieve EPC, S1 and internet links.

To reduce this waste of resources and increase user quality of experience, adding a cache and storage board in the BBU will allow the network to directly send the contents to users according to the need. The UE will only send an acknowledgement message to the $5 \mathrm{G} \mathrm{CN}$ to confirm that the contents have been received by the eNodeB. Accordingly, the possible structure of the $5 \mathrm{G}$ BBU would be presented as in Figure 7. In figure 7 a new cache and storage board is added in slot 6 of the $5 \mathrm{G} \mathrm{BBU}$. 


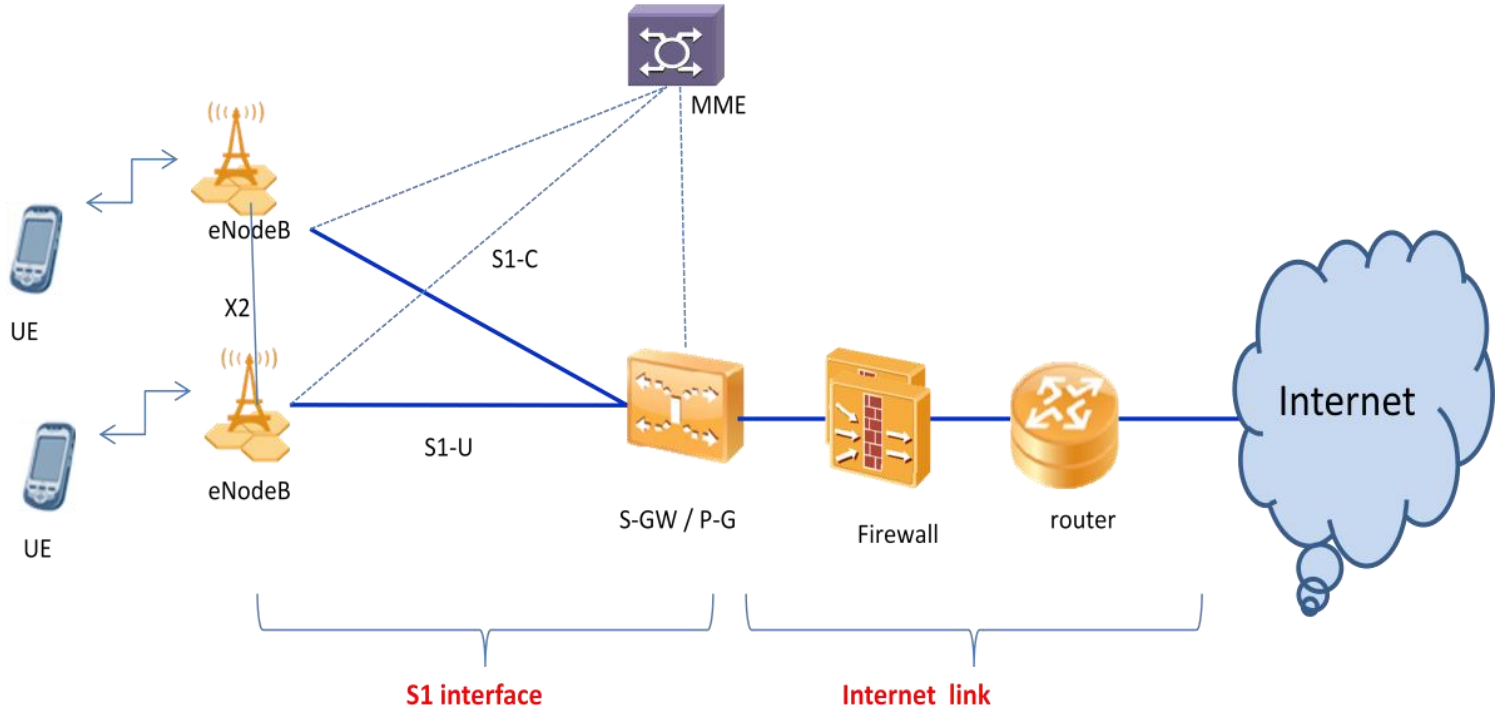

Fig 3: Diagram of a typical 4G network

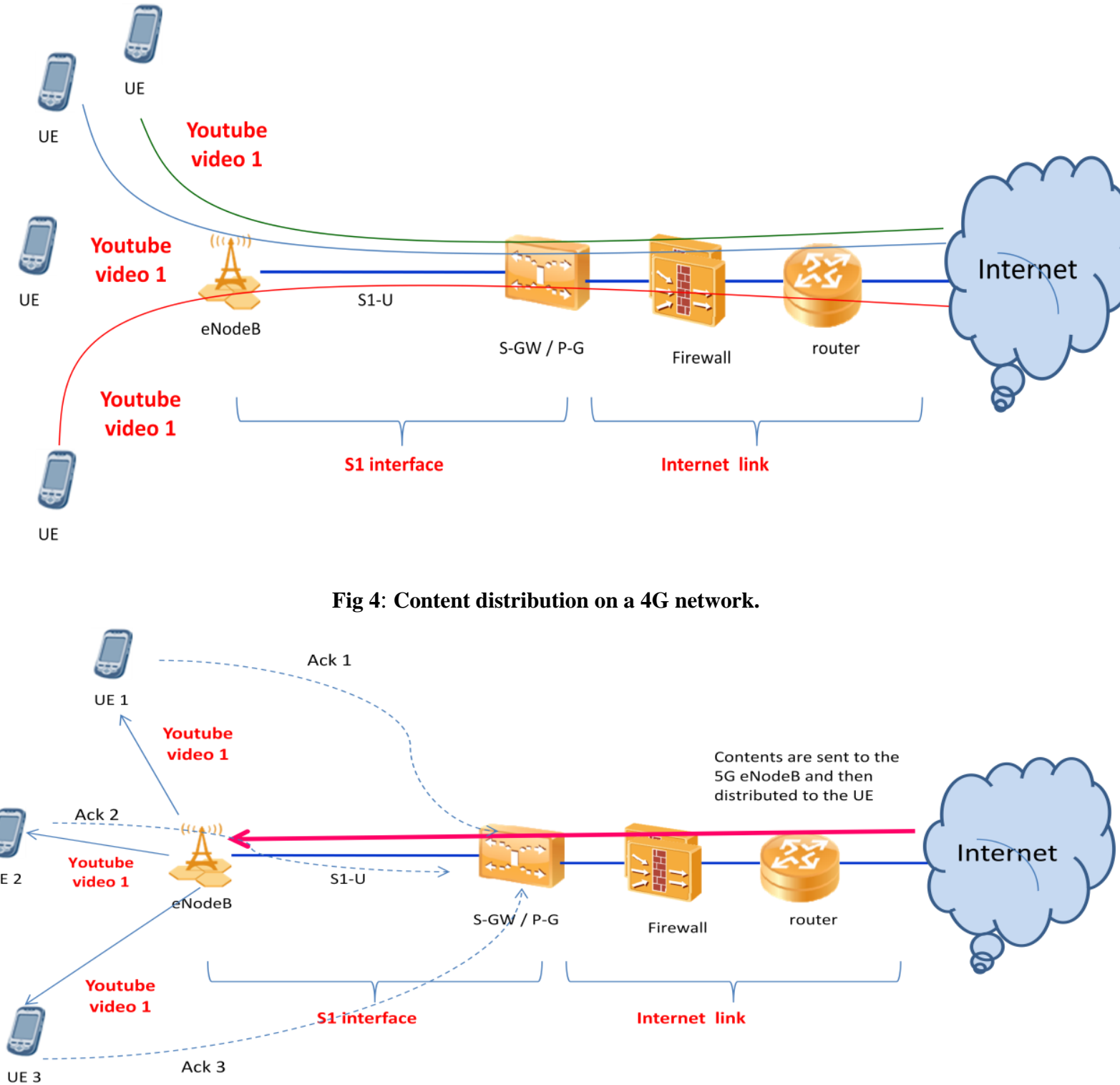

Fig 5: Improvement in bandwidth and capacity usage by adding a cache and storage board at the 5G eNodeB level. 


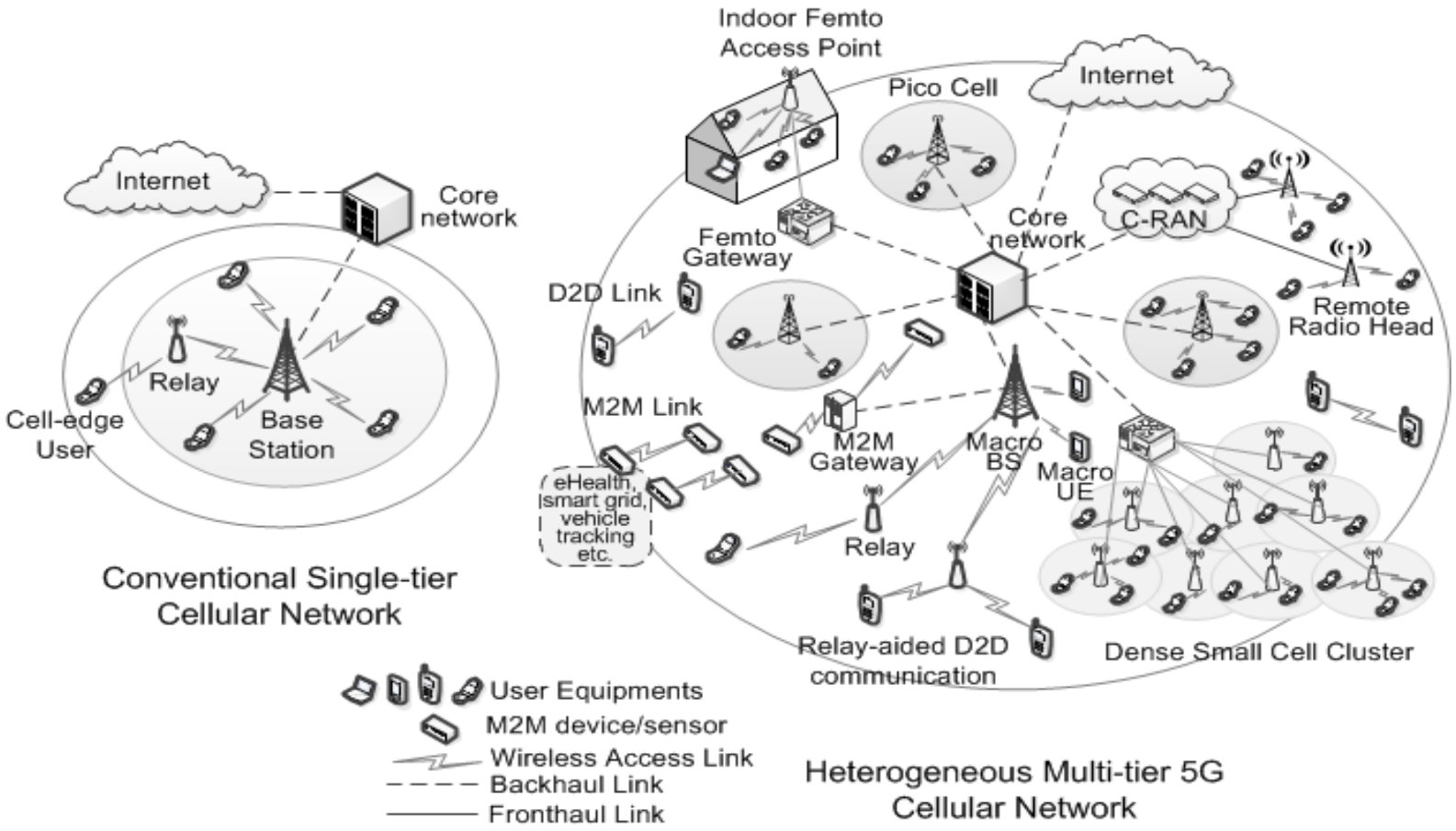

Fig 6: 5G networks and devices [11]

\begin{tabular}{|l|l|l|l|}
\hline \multirow{2}{*}{ Slot 0} & Slot 4 & \\
\cline { 2 - 4 } & Slot 1 & Slot 5 & \\
\cline { 2 - 4 } & Slot 2 & Slot(6) Cache and storage board & \\
\cline { 1 - 4 } & (Slot 3) Technology processing board & $\begin{array}{l}\text { (Slot 7) Management and transmission } \\
\text { board }\end{array}$ & \\
\hline
\end{tabular}

Fig 7: Improvement on BBU to have a new 5 G BBU solution with cache and storage unit

\section{EVALUATION OF THE SOLUTION ON THE 5G NETWORK}

The number of subscribers on an eNodeB is limited by the commercial license between the carrier and the eNodeB vendor. In Core network side S/P gateway capacity is limited by the number of simultaneous connections in one hand and also the processing throughput capability of the processing boards. Assuming $\mathrm{N}$ is the maximum number of subscribers of an eNodeB and $\mathrm{p}$ a proportion of them downloading simultaneously the same contents.

Let $\mathrm{D}$ be the maximum allowable throughput on an eNodeB, the average throughput per subscriber will be:

$D_{a v}=\frac{D}{p * N}$

If $\mathrm{S}$ is the size in Gigabit of a desired content, the downloading time of this content will be:

$t_{0}=\frac{S}{\left(\frac{D}{p * N}\right)}=\frac{p N S}{D}$

For $\mathrm{N}^{*} \mathrm{p}$ subscribers downloading simultaneously a desired content the resources of the processing board in charge of user plane at EPC level will be occupied $\mathrm{N}^{*} \mathrm{p}$ times compared to the occupation of a single subscriber and if there are $\mathrm{N}_{\mathrm{eNB}}$ eNodeB under the EPC downloading the same content, the occupied resources by this time will be multiplied by $\mathrm{N}_{\mathrm{eNB}}$.

Also if the content is downloaded successively by $\mathrm{N}^{*} \mathrm{p}$ subscribers, the EPC boards will be occupied during a time $\mathrm{t}_{\text {Total }}$, this time can be calculated according to the following relations:

$\mathrm{t}_{\text {Total }}=\mathrm{N} * \mathrm{p} * \mathrm{t}_{0}=\left(\mathrm{N} * \mathrm{p}^{2}\right) * \frac{\mathrm{NS}}{\mathrm{D}}$

Finally $\mathrm{t}_{\text {Total }}=\frac{\mathrm{N}^{2} * \mathrm{p}^{2} * \mathrm{~s}}{\mathrm{D}}$

if the content was stored on the eNodeB, it would be downloaded only once from the EPC and this during the time t0, the obtained gain in terms of occupation time would be:

$\mathrm{G}=\frac{\mathrm{t}_{\text {Total }}}{\mathrm{t}_{0}}=\mathrm{N} * \mathrm{p}$

For a network with an EPC managing $\mathrm{N}_{\mathrm{eNB}}$ eNode $\mathrm{B}$, this gain would be multiplied by $\mathrm{N}_{\mathrm{eNB}}$. And the final gain in this condition will be $\mathrm{G}_{\mathrm{T}}=\mathrm{N}_{\mathrm{eNB}} * \mathrm{G}=\mathrm{N} * \mathrm{p} * \mathrm{~N}_{\mathrm{eNB}}$

For example: if $\mathrm{N}=100, \mathrm{p}=10 \%$ and $\mathrm{NeNB}=500$, then the total gain will be GT $=5000$.

This solution helps relieve the $5 \mathrm{G}$ core Network load.

This total gain could be improved, for example if the eNodeB are grouped in a way that there exist X2 links between eNodeB of a group, they could share inside a group an available content meaning that if one eNodeB has stored a content, it informs the others (using X2 links) in the same group and no one of them will download it again from the $5 \mathrm{G}$ core. 
By this way a downloaded content is shared by a group of $\mathrm{m}$ eNodeB, the final gain could then be deduced as $G_{\text {final }}=m *$ $\mathrm{G}_{\mathrm{T}}$; with $\mathrm{m} \geq 1$. For the case $\mathrm{m}=1$, the group is reduced to single eNodeB.

The solution proposed in this paper will also help the operator to have distributed storage resources in all the coverage area of the mobile operator's network. In fact, If the available capacity per eNodeB is $10 \mathrm{~TB}$, and the operator has $\mathrm{N}_{\mathrm{eNB}}$ eNodeB, the total available distributed storage size will be: $10 \mathrm{~N}_{\mathrm{eNB}} \mathrm{TB}$. This distributed storage capability in the network could help for a lot of things in the future developments.

The proposed solution has the following advantages:

- $\quad$ Reduce S1 link usage;

- $\quad$ Reduce the load of the IP transport network in both the aggregation side and the IP core side;

- $\quad$ Reduce the load and usage of the 5G Core network. Only the acknowledgment messages and signaling negotiation messages are sent to the $5 \mathrm{G}$ core network;

- $\quad$ Reduce the load and usage on the internet link;

- Increase user quality of experience;

- Reduce latency on the network for multimedia services;

- Improve system quality of service globally;

- The storage and cache board could also be used by WiFi Access points to improve quality of service during LTE-WiFi interoperability.

- Distributed storage unit in the coverage area of the network

We also have the following disadvantages:

- Increase 5G eNodeB complexity;

- Need for standardization and normalization.

\section{CONCLUSION}

The 5G network design is a big challenge for both vendors and network operators. The quality of service and the quality of experience will have a big importance on $5 \mathrm{G}$ network. In this paper a proposal is done to improve the eNodeB capability by adding a cache and storage board that will improve the final user quality of service and reduce the load of S1 links, 5G core network and the internet link. The eNodeB in the coverage area of the EPC could also act as distributed storage unit. For future work, we can deeply analyze the distributed storage solution based on cache board on eNodeB and build a comparison between this solution and the peer to peer networking. A deeper investigation of contents shared over X2 interface could be done also.

\section{REFERENCES}

[1] Network architecture for the $5 \mathrm{G}$ era; white paper, page 1; Nokia Solutions and Networks 2015. Available Online:http://networks.nokia.com/sites/default/files/docu ment/nokia_5g_architecture_white_paper.pdf

[2] Network architecture for the 5G era; white paper, page 5; Nokia Solutions and Networks 2015. Available Online:http://networks.nokia.com/sites/default/files/docu ment/nokia_5g_architecture_white_paper.pdf

[3] Hossain, E., \& Hasan, M. (2015). 5G cellular: key enabling technologies and research challenges. Instrumentation \& Measurement Magazine, IEEE, 18(3), $11-21$.

[4] P. Demestichas, A. Georgakopoulos, D. Karvounas, K. Tsagkaris, V. Stavroulaki, J. Lu, C. Xiong, and J. Yao, " $5 \mathrm{G}$ on the horizon: Key challenges for the radio-access network," IEEE Vehicular Technology Magazine, vol. 8, no. 3, pp. 47-53, Sept. 2013.

[5] A. Zakrzewska, S. Ruepp, and M. Berger, "Towards converged 5G mobile networks - Challenges and current trends," in Proc. ITU Kaleidoscope Academic Conference, pp. 39-45, Jun. 2014.

[6] S. Talwar, D. Choudhury, K. Dimou, E. Aryafar, B. Bangerter, and K. Stewart, "Enabling technologies and architectures for 5G wireless," in Proc. IEEE MTT-S International Microwave Symposium (IMS), pp. 1-4, Jun. 2014.

[7] Chandan Pradhan et al, Full-Duplex eNodeB and UE Design for 5G Networks. arXiv preprint arXiv:1506.02132

[8] https://www.alcatel-lucent.com/products/alcatel-lucent9926-enodeb [ONLINE], accessed on 28/02/2016.

[9] Alcatel-Lucent_9926-Digital-2U-eNode-B_datasheet.

[10] 3900 Series Base Station Product Documentation Product Version: V100R009C00 Date: 5/30/2015, HUAWEI Technologies, Hedhexlite, page 900/23608.

[11] Ekram Hossain and Monowar Hasan, 5G Cellular: Key Enabling Technologies and Research Challenges, Department of Electrical and Computer Engineering, University of Manitoba, Canada page 4. 